\title{
A Comparison of Aircraft and Jimsphere Wind Measurements
}

\author{
D. S. Treddenick \\ National Aeronautical Establishment, National Research Council of Canada, Ottawa
}

(Manuscript received 4 August 1970, in revised form 23 November 1970)

\section{ABSTRACT}

\begin{abstract}
Gpper level wind profiles obtained from a Doppler equipped aircraft and from radar tracking of a Jimsphere balloon are compared. Simultaneous measurements were made by these methods on 19 and 20 February 1970. The measurements agree closely in terms of rms variation and power spectral density. The effect of small horizontal separation of the measurements $(\sim 10 \mathrm{n} \mathrm{mi})$ was found to be insignificant.
\end{abstract}

\section{Introduction}

During project Haven Hop in January and February 1970, simultaneous upper wind measurements were made by a Doppler radar-equipped aircraft and by radar tracking of a Jimsphere balloon. The measurements were made near Wallops Island, Va., by the Joint Air Force-NASA radar facility and by a $T-33$ aircraft from the National Aeronautical Establishment, Canada. Project Haven Hop was concerned primarily with a study of clear air turbulence but a by-product of the program was the opportunity to make coordinated fine-scale wind measurements. These measurements have allowed a comparison of the accuracy and fidelity of vertical wind profiles obtained from two widely different techniques.

A major difference between the two methods is that the Jimsphere translates with the magnitude and direction of the mean flow whereas the T-33 moves in a predetermined direction at its true air speed plus the wind vector. However, provided the measurements are made reasonably close together in space and time and that longitudinal fluctuations in the mean flow are not significant, then the comparison should still be valid.

Numerous sources of error are present in each system. In the FPS-16 radar/Jimsphere system, the accuracy of winds computed over $50 \mathrm{~m}$ layers is affected most

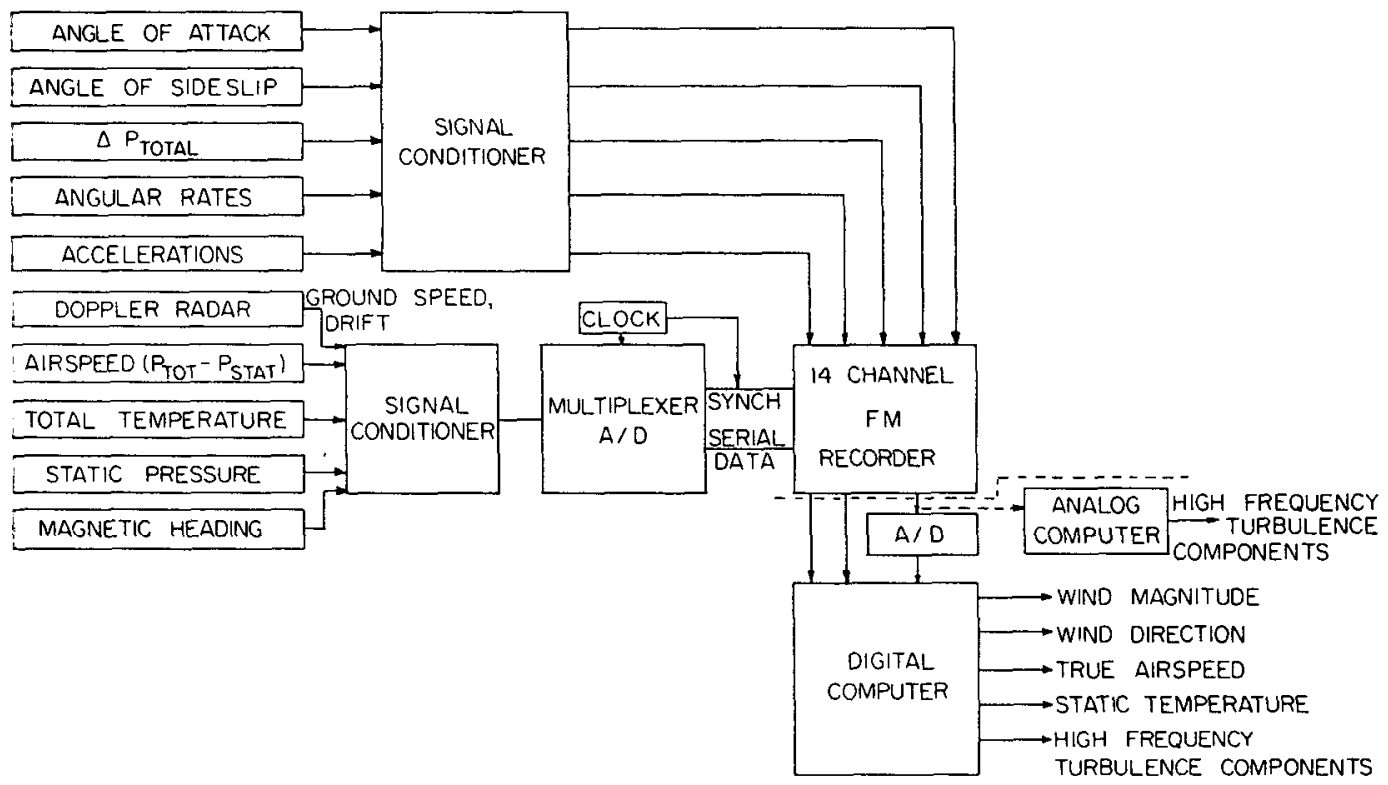

FIG. 1. Functional block diagram of T-33 instrumentation system.

'A collaborative clear air turbulence research program directed by Dr. K. Hardy of the Air Force Cambridge Rescarch Laboratories. 


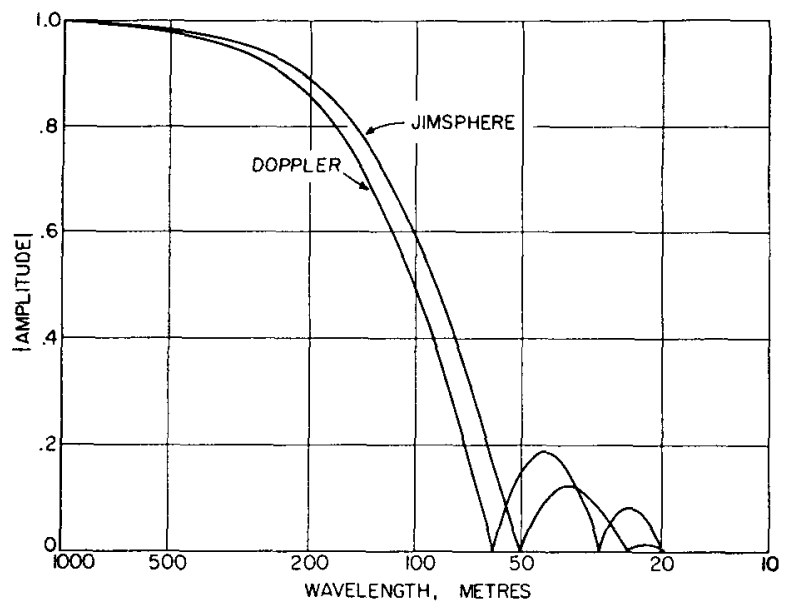

FIG. 2. Characteristics of filters used in processing Doppler and Jimsphere winds.

significantly by: 1) excessive noise and nonstationarity of the raw radar data, 2) stray points and data shifts that elude the editing/smoothing procedure, 3) lag in the radar antenna response, and 4) erratic balloon motions. These errors are discussed in some detail by Scoggins and Armendariz (1969). This study also indicates that rms errors in Jimsphere winds due to errors in the radar data are less than $1.0 \mathrm{~m} \mathrm{sec}^{-1}$.

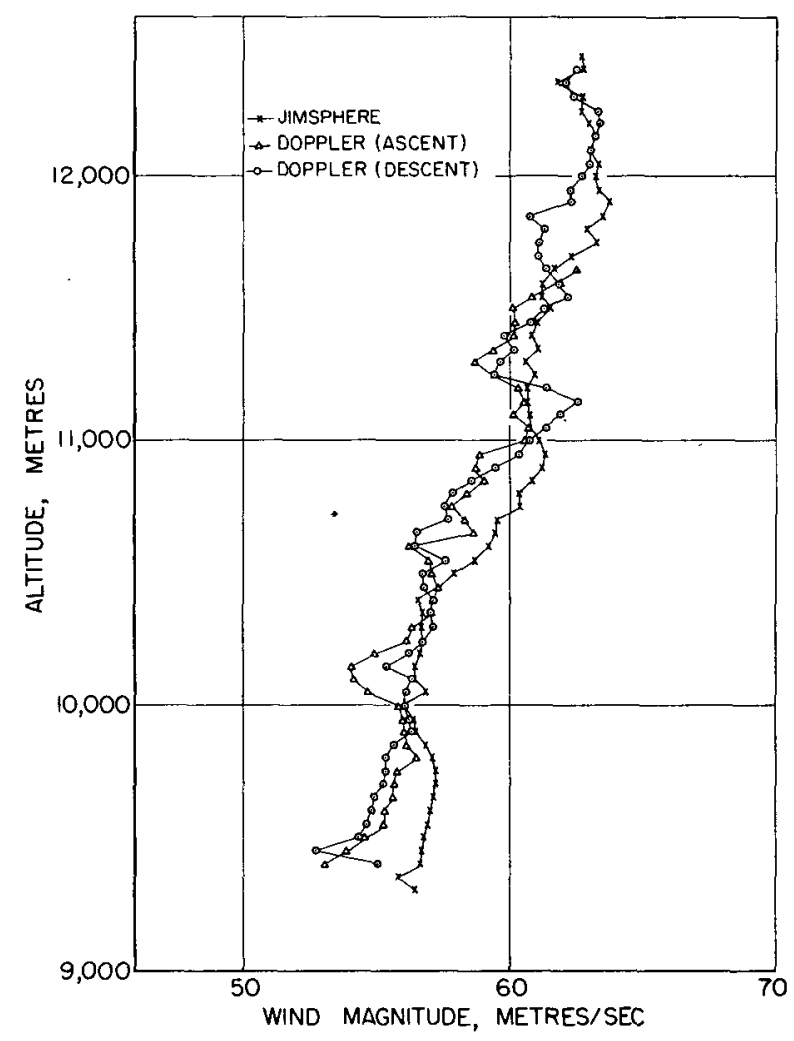

FIG. 3. Jimsphere and Doppler wind profiles measured on 19 February 1970.
In the aircraft-Doppler system errors of wind measurement arise from errors in the ground speed vector as measured by the Doppler radar and also from errors in the true airspeed as obtained from recordings of indicated airspeed, altitude, total temperature, and magnetic heading. The Doppler radar used in the T-33, a GPL AN/APN-153(V), can determine ground speed and drift angle to within $0.17 \%$; while the airspeed, altitude, and temperature sensors provide a measure of true airspeed to within less than $1 \%$. These factors combine to produce rms wind speed errors of less than $1.5 \mathrm{~m} \mathrm{sec}^{-1}$. Some of the errors involved in wind measurements from aircraft using Doppler radar systems are discussed by Axford (1968).

\section{Aircraft instrumentation system}

A functional block diagram of the T-33 instrumentation system is shown in Fig. 1. The outputs from the Doppler radar and the sensors used to compute true airspeed are multiplexed and recorded on one channel of the FM recorder. The clock sets the sample rate (presently 2.5 samples per second) and also provides synchronization for later recovery of the data. On playback of the recorded data, the wind vector is established simply by adding the airspeed and ground speed vectors.

Rapidly varying wind components are determined by recording the necessary parameters (see block diagram) in an analog form on the FM recorder. The two systems

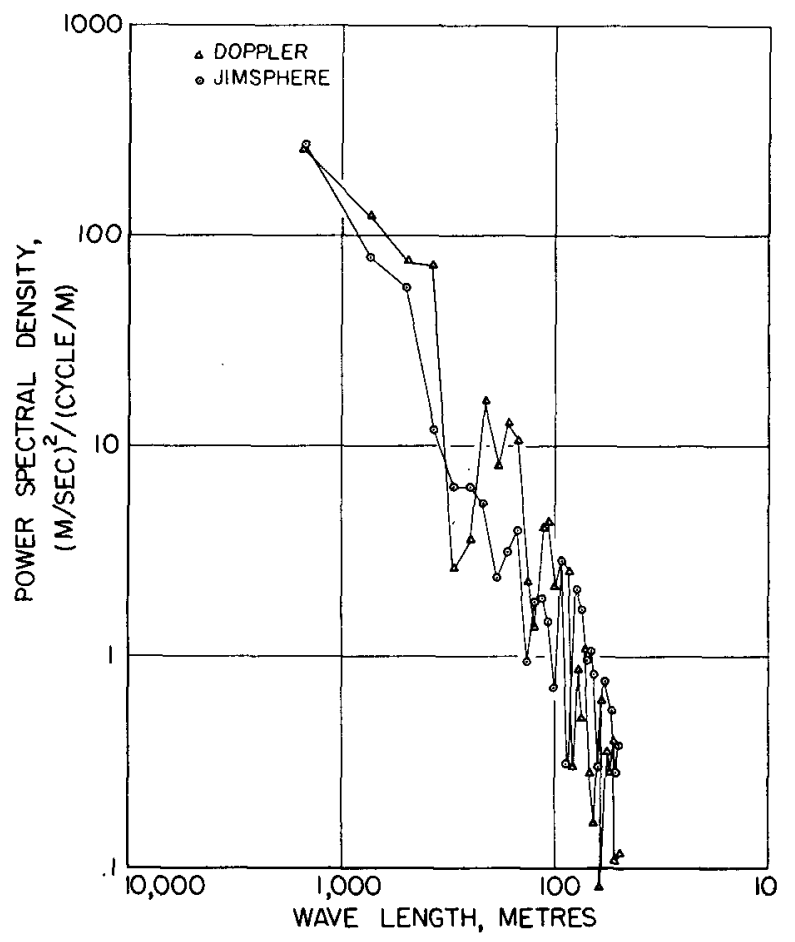

FIG. 4. Comparison of power spectral density of Jimsphere and Doppler winds, 19 February 1970. 


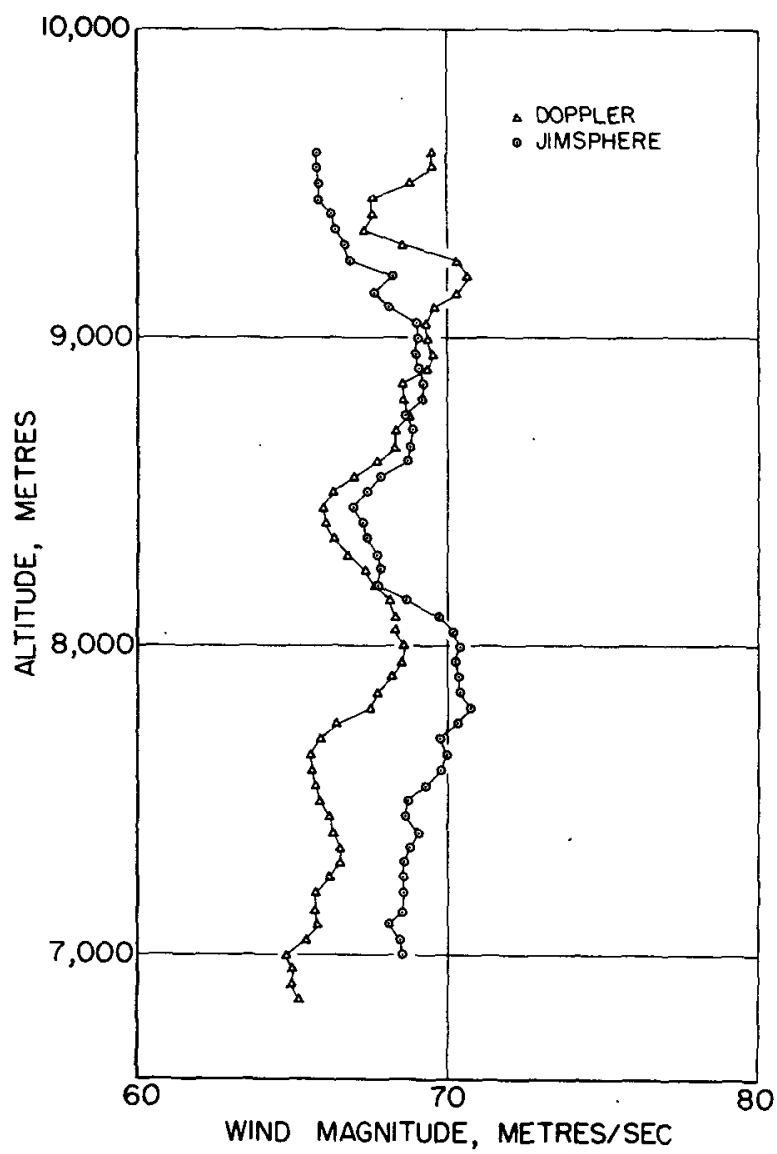

FIG. 5. Jimsphere and Doppler wind profiles measured on 20 February 1970.

overlap in frequency response and together provide for wind measurements from 0 to $10 \mathrm{~Hz}$.

In order to make the comparison more meaningful, care has been taken to filter the Doppler data in a manner similar to that used for the Jimsphere. The

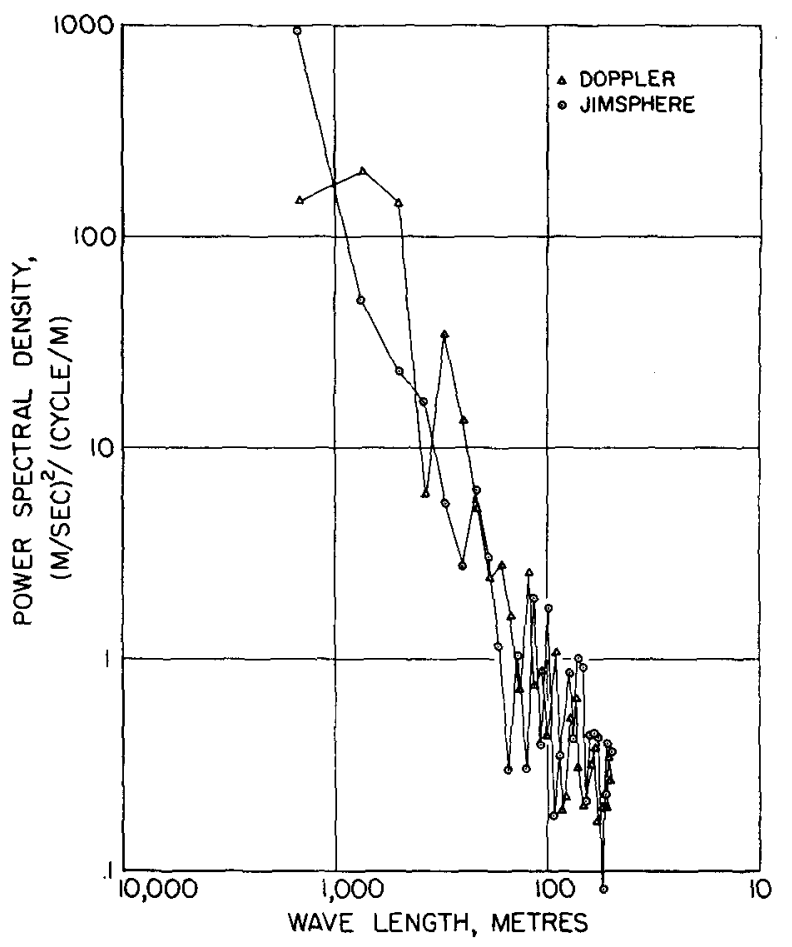

FtG. 6. Comparison of power spectral density of Jimsphere and Doppler winds, 20 February 1970.

digital filters used in each case are of the form

$$
\frac{(\sin k \pi \alpha)\left(\sin k^{\prime} \pi \alpha\right)}{k k^{\prime} \pi^{2} \alpha^{2}}
$$

where $k$ and $k^{\prime}$ are constants and $\alpha$ is wavenumber (cycles $\mathrm{m}^{-1}$ ). The attenuation caused by each of the filters is shown in Fig. 2.

After filtering as shown above, power spectra of the Doppler and Jimsphere winds were computed using the fast Fourier Transform method, covering the wavelength range from 50 to $1500 \mathrm{~m}$.
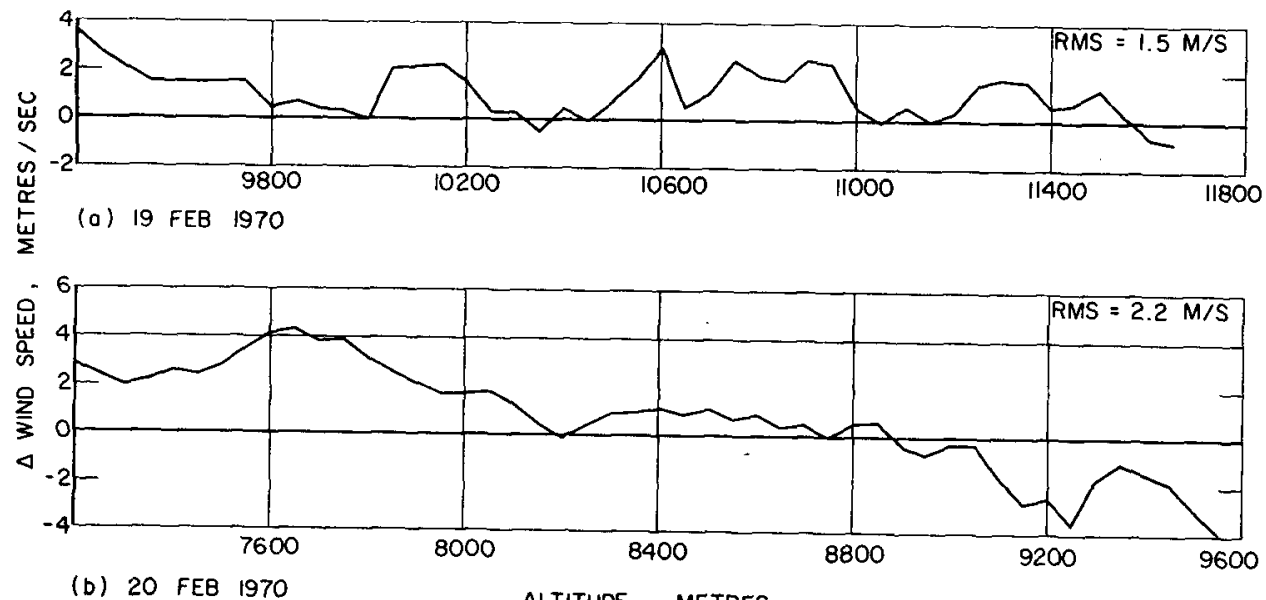

FIG: 7. Difference in wind speed measured by Doppler and Jimsphere. 


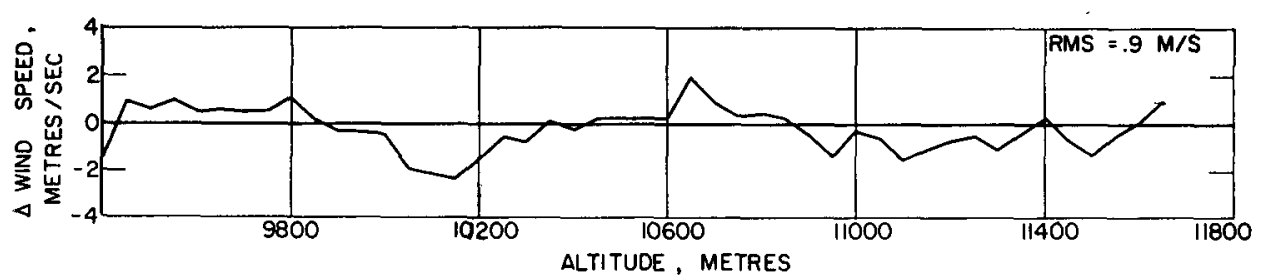

FIG. 8. Difference between Doppler wind profiles measured during ascent and descent on 19 February 1970.

\section{Results}

On 19 February 1970 a coordinated aircraft and Jimsphere wind sounding was carried out in the vicinity of Wallops Island, Va. The aircraft measurements were made between 9400 and $12,400 \mathrm{~m}$ during an ascent into wind and a descent downwind. At the time of the Jimsphere launch the aircraft was in a holding pattern $20 \mathrm{mi}$ off the Virginia coast and commenced its ascent at a time calculated for the Jimsphere to have arrived at the holding altitude. The aircraft ascent rate was matched as nearly as possible to the Jimsphere rate of rise $\left(\sim 5 \mathrm{~m} \mathrm{sec}^{-1}\right)$ and it is considered that the two measurements were made over the same altitude band during the same time interval, although separated possibly horizontally by several miles. Fig. 3 shows a comparison of the detailed wind soundings made by the two systems, while Fig. 4 shows the two power spectra. Fig. 3 also includes the result of the descent sounding carried out $\sim 10 \mathrm{mi}$ further upwind.

A second coordinated wind sounding was made at the same location on 20 February 1970 . The measurement technique was similar to that used on the first sounding and consisted of an upwind ascent between 7000 and $9600 \mathrm{~m}$. Comparison of the fine-scale wind profiles and power spectra obtained from this sounding are shown in Figs. 5 and 6, respectively.

\section{Conclusions}

Reasonably good agreement has been found between upper-level wind profiles obtained from radar tracking of a Jimsphere balloon and from a Doppler radar equipped aircraft. The comparison is examined in Fig. 7 in terms of a point-by-point difference in wind speed at the same altitude. The rms values of the difference between measurements were calculated from this figure and are shown there as $1.5 \mathrm{~m} \mathrm{sec}^{-1}$ for the sounding on 19 February and $2.2 \mathrm{~m} \mathrm{sec}^{-1}$ for the sounding on 20 February. These rms values are very close to the noise figures of the systems and suggest that any difference in the soundings due to horizontal separation of the measurements is very small. The effect of horizontal separation on the measurements is also shown to be small from a comparison of the aircraft ascent and descent wind profiles on 19 February (Fig. 8). The rms value in this case is only $0.9 \mathrm{~m} \mathrm{sec}^{-1}$. The major difference between the wind profiles appears in the finescale shear over some layers. However, in general, the two measurements agree to within at least $0.005 \mathrm{sec}^{-1}$ for shears averaged over, say, $200 \mathrm{~m}$.

Power spectra of the Jimsphere and Doppler wind profiles suggest a very similar energy distribution over the range of wavelengths considered $(50-1500 \mathrm{~m})$. The spectra were computed using only four degrees of freedom and are not considered statistically representative of upper-level wind profiles. The spectra have average slopes of approximately -2.5 in contrast to a previous investigation where a -3 power law was observed (Collis et al., 1968). The slopes of the Doppler spectra do, however, agree with the average of several hundred Jimsphere profiles presented by Scoggins (1969).

Measurements similar to those described in this note are planned for early 1971, and it is expected that through improvements in the FPS-16 radar data processing (De Mandel, 1970), and recent improvements in the T-33 instrumentation, even closer' agreement should be found between Doppler and Jimsphere wind profiles.

Acknowledgments. The writer is grateful to Dr. George Fichtl, of NASA Marshall Space Flight Center, for so promptly supplying the Jimsphere data. $\mathrm{He}$ is also grateful to the Director of the National Aeronautical Establishment, Ottawa, Canada, for permission to publish these results.

\section{REFERENCES}

Axford, D. N., 1968: On the accuracy of wind measurements using an inertial platform in an aircraft, and an example of a measurement of the vertical mesostructure of the atmosphere. J. Appl. Meleor., 7, 645-666.

Collis, R. T., R. M. Endlich and R. L. Mancuso, 1968: Recent studies related to clear air turbulence. Proc. Symp. on Clear Air Turbulence and its Detection, Seattle, 361-377.

De Mandel, R. E., 1970: Optimum filters for deriving winds from FPS-16 radar/Jimsphere measurements. Proc. Fourth Natl. Conf. Aerospace Meteorology, Las Vegas, Nev., Amer. Meteor. Soc., 136-143.

Scoggins, J. R. 1969: Wind effects on launch vehicles. Chap. 2, AGARDograph 115, Technivision Services, Slough, England, 33-72.

- and Manuel Armendariz, 1969: On the measurement of winds by the AN/FPS-16 radar/spherical balloon method. J. A ppl. Meteor., 8, 449-452. 